\title{
INVISÍVEIS NA CIDADE: INVISIBILIDADE SOCIAL NOS LIVROS ILUSTRADOS CONTEMPORÂNEOS
}

\author{
Silvana Gili ${ }^{69}$
}

RESUMO: A questão a ser explorada neste trabalho relaciona-se às formas de representação verbo-visual das relações entre personagens nos espaços urbanos retratados nas produções literárias atuais. Este artigo é desenvolvido no intuito de analisar os contatos entre personagens que representam facetas opostas/distintas dessas relações sociais. O objetivo é avaliar a perspectiva desde a qual essas relações são apresentadas ao leitor e qual discurso reforçam e/ou questionam. Quais espaços para o diálogo abrem (ou não)? Que novas analogias e trajetos do pensamento permitem? Desse modo, busco entender como a literatura reage às relações de individuos que vivenciam extremas desigualdades sociais, explorando imagens literárias que constroem a maneira como enxergamos os lugares, os personagens da cidade, e a forma como se relacionam. Para desenvolver essa ideia, farei a análise de dois livros ilustrados publicados recentemente, Os Invisiveis (Ed. Casa da Palavra, 2012), de Tino Freitas e Renato Moriconi e Fábula Urbana (Edições de Janeiro, 2014) de José Rezende Jr. e Rogério Coelho, concentrando-me em três aspectos, quais sejam, os personagens, os espaços por onde circulam, e as interações que se dão entre eles nesses espaços.

Palavras-chave: invisibilidade social; livros ilustrados; espaços urbanos.

ABSTRACT: The main issue to be discussed in this article relates to the forms of verbal-visual representation of urban character relations depicted in contemporary literary media. The purpose of this article is to analyze the perspective from which various social relations, especially those that illustrate characters from opposite sides of these relations, are presented to the readers and which kind of discourse they reinforce and/or question. What kind of space for dialogue do they open (or not)? What new analogies and thought trajectories do they allow? This article is an intent to understand how literature reacts to the relationship of individuals that live in extreme social inequality realities, by exploring

${ }^{69}$ Doutoranda em Literatura pela Universidade Federal de Santa Catarina-UFSC. 
literary images that construct the way we view city spaces, city characters, and the way the relate to each other. In order to develop that idea, I will analyze two recently published picturebooks: Os Invisiveis (Ed. Casa da Palavra, 2012), written by Tino Freitas and illustrated by Renato Moriconi, and Fábula Urbana (Edições de Janeiro, 2014) written by José Rezende Jr. and illustrated by Rogério Coelho. My analysis will focus on three aspects: urban characters, the urban spaces around which they circulate, and the interactions that take place between these characters in such spaces.

Keywords: social invisibility; picture books; urban spaces.

Ao sair em busca do espaço urbano mapeado pela narrativa contemporânea, nos deparamos, de algum modo, com o lugar da cidade em nossas vidas e com o não-lugar de muitas vidas em nossas cidades. O mapa que procurávamos talvez não traga mais que alguns rabiscos, desenhos sem muita continuidade, que precisam ser afastados de nossos olhos para que consigamos ver ali algo reconhecivel. E esse reconhecivel pode ser nosso próprio rosto, confuso, assustado, meio caricato até. Afinal, somos nós que preenchemos os vazios da cidade, nós que a fazemos existir. Somos responsáveis por suas injustiças, por sua violência, sua segregação. Somos culpados pelo que não queremos ver. Regina Dalcastagné

\section{Introdução}

O termo invisibilidade social no subtítulo deste artigo refere-se ao apagamento de uma pessoa enquanto ser humano com traços individuais que a distinguem de outras pessoas. Esse conceito de invisibilidade resulta de uma reflexão contemporânea a respeito das desigualdades sociais acentuadas pelo capitalismo. $O$ termo tem sido usado para designar minorias ou grupos socialmente marginalizados devido ao preconceito ou 
Invisíveis na cidade: invisibilidade social nos livros ilustrados contemporâneos | 185

à indiferença. Isso ocorre em um contexto onde relacionamentos são hierarquizados e afeta aqueles que estão à margem da sociedade devido a razões econômicas e/ou culturais. Sendo assim, este é um tema que propõe uma discussão bastante relevante a respeito do papel de cada individuo na sociedade e no reconhecimento de sua identidade nos mais diversos contextos sociais já que coloca em questão a crise dos relacionamentos individuais na sociedade moderna.

O tema da invisibilidade das margens tem ocupado a atenção de programas sociais e veículos de comunicação há algumas décadas. $\mathrm{O}$ processo de tentativa de conscientização parece atuar sob duas vertentes: tanto chama a atenção para essas diferenças quanto reforça as fronteiras físicas ou não - que separa os grupos sociais dentro do espaço urbano ${ }^{70}$. Apesar de acreditar na importância do reconhecimento dos espaços marginais e periféricos, o que me interessa realmente é investigar os espaços comuns, ou seja, o lugar onde personagens advindos de esferas sociais diferentes se encontram e se reconhecem como co-participantes da experiência humana. Esses espaços nem sempre são verdadeiramente comuns, muito pelo contrário. No entanto, ao não se vincularem, declaradamente, ou inevitavelmente, a um grupo social específico, criam um espaço de encontro possivel, borrando as margens e tornando-as permeáveis.

\section{Margens, Fronteiras, Limiares}

Questões relativas às separações e fronteiras (físicas, econômicas ou culturais) entre diferentes classes sociais representadas na literatura têm sido problematizadas por pesquisadores de diversas áreas nos últimos anos e o tema cidade é recorrente nos estudos literários contemporâneos e recentes. Prova disso são os vários dossiês temáticos de periódicos acadêmicos dedicados ao assunto ${ }^{71}$ e mesas redondas organizadas em distintos eventos literários que buscam discutir as questões da cidade e

\footnotetext{
${ }^{70}$ Exemplo disso são os processos de gentrificação nas grandes cidades os quais têm sido bem documentados em projetos como Arquitetura da Gentrificação, da jornalista Sabrina Duran, e em obras como De Volta à Cidade, organizada pela socióloga Catherine BidouZachariasen.

${ }^{71}$ Ver, por exemplo, o dossiê temático publicado no n. 8 da Revista Outra Travessia (UFSC, 2009) que se intitulou Cidades da periferia, periferia das cidades; ou, mais recentemente, o n. 42 da Revista de Estudos de Literatura Brasileira Contemporânea (UnB, 2013) que se intitulou Literatura e Espaço Urbano.
} 
suas complexidades ${ }^{72}$. Para Regina Dalcastagné e Luciene Azevedo, a cidade "não é um espaço homogêneo, mas fragmentado e, sobretudo, hierarquizado, marcado por interdições tácitas, que definem quais habitantes podem ocupar quais lugares" (DALCASTAGNÉ e AZEVEDO, 2015, p. 12).

Este artigo vem se unir a essa perspectiva, buscando, no entanto, concentrar o olhar não nos extremos que se opõem, mas sim nas situações de encontro entre os personagens das cidades e os espaços comuns por onde transitam, a fim de, assim como Dalcastagné e Azevedo, "discutir as tensões estabelecidas a partir de relações conflituosas com o espaço vivenciadas dentro e no entorno das obras." (2015, p.11). Nesse sentido, interessa-me pensar limiares mais que fronteiras, zonas de deambulação que se abrem a trocas e permutas e que propiciam, assim, transformações. Raymond Williams apontava para o surgimento, no século XX, de uma consciência coletiva "capaz de ver não apenas os indivíduos mas também os relacionamentos entre eles, alterados e em processo de alteração, e de, ao ver os relacionamentos e suas causas sociais, encontrar meios sociais de transformação" (WILLIAMS, 2011, p. 405). Essa transformação só pode surgir a partir das interações. Os conflitos, ainda que possuam conotação negativa, são sempre desencadeadores de reflexões.

$O$ personagem de Ralph Ellison foi o primeiro a levantar, na literatura, a questão da invisibilidade social. $\mathrm{O}$ parágrafo de abertura de $\mathrm{O}$ Homem Invisivel dá ao leitor a chave de leitura do romance:

Sou um homem invisivel. Não, não sou um fantasma como os que assombravam Edgar Allan Poe; nem um desses ectoplasmas de filme de Hollywood. Sou um homem de substância, de carne e osso, fibras e líquidos - talvez se possa até dizer que possuo uma mente. Sou invisível, compreendam, simplesmente porque as pessoas se recusam a me ver. Tal como essas cabeças sem corpo que às vezes são exibidas nos mafuás de circo, estou, por assim dizer, cercado de espelhos de vidro duro e deformante. Quem se aproxima de mim vê apenas o que me cerca, a si mesmo, ou os inventos de sua própria imaginação - na verdade, tudo e

\footnotetext{
${ }^{72}$ Desde 2009, a Festa Literária de Paraty - FLIP - organiza a "Mesa Zé Kleber", dedicada a discutir a cidade e suas politicas públicas. Todos os anos a FLIP organiza, também, uma ou mais "Mesas de Arquitetura" que abordam questões de arquitetura e urbanismo na atualidade.
} 
Invisíveis na cidade: invisibilidade social nos livros ilustrados contemporâneos | 187 qualquer coisa, menos eu. (ELLISON, trad. Márcio Serra, $1952)^{73}$

O protagonista de Ellison afirma, nesse parágrafo, que era invisível simplesmente porque as pessoas se recusavam a lhe ver. Nessa recusa, eliminavam qualquer possibilidade de interação, obliterando sua própria presença no meio social. O protagonista referia-se ao fato específico de ser invisivel porque era negro, mas pode-se ampliar a questão para abarcar grupos identitários diversos na consideração dos aspectos políticos que ela contempla. Quem são, afinal, esses personagens invisiveis? Por que são invisíveis? São invisíveis porque assim o desejam? Ou são invisíveis porque falta-lhes o reconhecimento do olhar do outro?

\section{Livro Ilustrado}

Desviar o olhar e negar ao outro sua própria constituição é uma tentativa de manter o status quo. Aspectos vários dos contrastes entre as classes permeiam a criação artística atual, criação esta que muitas vezes apoia-se no visual como forma de expressão. O questionamento em relação à invisibilidade de personagens da sociedade atual pode ser feito também em relação às diversas formas contemporâneas de expressão artística em se considerando que são produtos culturais. Se as dinâmicas urbanas concentram padrões e tendências que passam desapercebidos pelo olhar, as expressões artísticas, e entre elas a literatura, parecem ter a capacidade de ressaltar pontos invisíveis ao olho nu e, em algumas instâncias, propor olhares alternativos. No caso dos livros ilustrados, é interessante observar como as ilustrações por vezes mostram de maneira muito clara esses pontos obscuros. O leitor posiciona-se ao buscar conciliar a tensão existente entre texto visual e texto escrito, construindo de forma ativa aquilo que o texto lhe diz/mostra.

O livro ilustrado é um objeto cultural que representa uma forma de expressão artística visual e literária única pois conjuga texto escrito e texto visual para a construção da narrativa. É dentre a produção brasileira

\footnotetext{
${ }^{73}$ No original em inglês: "I am an invisible man. No, I am not a spook like those who haunted Edgar Allan Poe; nor am I one of your Hollywood-movie ectoplasms. I am a man of substance, of flesh and bone, fiber and liquids - and I might even be said to possess a mind. I am invisible, understand, simply because people refuse to see me. Like the bodiless heads you see sometimes in circus sideshows, it is as though I have been surrounded by mirrors of hard, distorting glass. When they approach me they see only my surroundings, themselves, or figments of their imagination - indeed, everything and anything except me." (ELLISON, 1952)
} 
direcionada a crianças e jovens que se encontra o maior volume de livros ilustrados ${ }^{74}$ o que explica a escolha dos dois titulos a serem analisados neste artigo. A literatura infantil, como qualquer forma de expressão artística, reflete valores da sociedade, atitudes e conhecimentos pertencentes ao momento histórico em que é criada, repercutindo, de maneira ampla, o movimento histórico, social e cultural. Nesse sentido, é válida a reflexão acerca da produção de livros ilustrados sejam eles direcionados às crianças ou não.

Em alguns livros ilustrados, palavra e imagem se entrelaçam na construção do texto e a ausência de qualquer um dos dois elementos muda radicalmente o sentido do mesmo. A narrativa depende, assim, da interação entre texto escrito e texto visual - ambos tendo sido criados com intenções estéticas precisas e conscientes. O livro ilustrado representa, portanto, mais do que a soma das duas partes. Lawrence Sipe (1998) aponta a relação texto e imagem como sendo sinergética. Nikolajeva e Scott (2011) explicam que nos livros ilustrados a função das palavras é, principalmente, narrar, e a função das ilustrações é descrever ou representar. A tensão gerada pela presença de ambas no livro gera possibilidades diversas de interação entre palavras e ilustrações e cria um enigma a ser resolvido pelo leitor. De acordo com essa visão, texto e imagem nunca contam exatamente a mesma história e é justamente essa dissonância que captura a atenção do leitor. Assim, o leitor é parte ativa da construção da narrativa já que precisa trabalhar para resolver esse "conflito" entre texto e imagem (NIKOLAJEVA e SCOTT, 2011). Para diferenciar esse tipo de livro ilustrado dos demais livros com ilustrações, alguns autores têm usado o termo livro álbum, seguindo a nomenclatura utilizada em países hispano-falantes (libro álbum), Portugal (livro álbum), França (album illustré) e Itália (albo illustrato), por exemplo.

Segundo Sophie Van der Linden, no livro álbum "tudo tem sentido pois ele é concebido como um sistema global onde os principais componentes participam, em graus diferentes, da produção de sentido" (2013, p. 35, tradução minha). Assim, todos os seus elementos, tanto materiais quanto de conteúdo, tornam-se essenciais. Para ler o livro álbum, portanto, é necessário aguçar a visão e considerar todos os elementos nele presentes. $O$ olhar treinado para abarcar tudo o que

\footnotetext{
${ }^{74}$ Algumas editoras europeias, como a Media Vaca (Espanha), Libros del Zorro Rojo (Espanha), e Barbara Fiore (Itália) e asiáticas, como a Tara Books (Índia), têm coleções de livros álbum direcionados ao público adulto. No Brasil, a editora Cosac Naify começa a lançar versões ilustradas de textos de autores consagrados como Eça de Queirós e Kafka.
} 
Invisíveis na cidade: invisibilidade social nos livros ilustrados contemporâneos | 189 compõe uma narrativa ilustrada logo começa a perceber, porém, os elementos ausentes dessas narrativas. É daquilo que não aparece nunca, ou que aparece com pouca frequência, que trata este trabalho. Sendo assim, os livros escolhidos para análise apresentam personagens incomuns nas narrativas ilustradas.

O primeiro deles é Os Invisíveis (Ed. Casa da Palavra, 2012), de Tino Freitas e Renato Moriconi, mencionado anteriormente. O enredo trata de um menino que tinha um superpoder, manifestado no livro pela cor laranja. Só ele na família era capaz de enxergar os invisíveis, habilidade que fica estabelecida pelo raio que sai de seus olhos. Mas é apenas na terceira página dupla (p. 12-13) que se esclarece quem são os invisiveis a que se refere o título: garis, pedintes, porteiros, garçons personagens da cidade que nesse livro são representados apenas por meio de ilustrações cinzentas, tornando-se, assim, imagens em sombra, silhuetas sem rosto, sem traços distintivos; através das quais pode-se enxergar. Em Os Invisiveis, o jogo entre palavra e imagem acontece a partir da capa. Dos olhos do pequeno menino, posicionado no canto inferior esquerdo, ao lado dos nomes dos autores, desponta um "raio" alaranjado que alcança o título no topo. O raio atravessa a palavra 'invisíveis' separando-a em duas partes: 'in-visíveis'. A parte visível passa então a ser cinzenta, nebulosa, deixa de ser bem definida. Essa parece ser a premissa do livro. O olhar aguçado pode ver, mas nem tudo o que é visível está claro.

O segundo livro - Fábula Urbana (Edições de Janeiro, 2014) - é escrito por José Rezende Jr. e ilustrado por Rogério Coelho. Este livro tem como cenário um espaço comumente associado com a classe média no Brasil: o shopping center. Aqui, dois personagens interagem a partir de um pedido totalmente incomum. Acostumado a crianças em semáforos e ruas pedindo trocados, o protagonista adulto é surpreendido por um menino sujo e mal-vestido que dele se aproxima para pedir um... livro. A surpresa, no entanto, não esconde o aborrecimento do adulto incomodado por um personagem que, em sua opinião, não pertence àquela esfera. $\mathrm{O}$ intercâmbio entre os dois enfatiza as noções de espaços destinados a um e outro grupos sociais. Sua interação rápida também questiona as relações entre diferentes pessoas em diferentes espaços. $\mathrm{O}$ final surpreendente procura desarticular sentimentos preconcebidos e preconceitos. 


\section{Caracterização dos personagens}

Assim como o narrador de Ellison, muitos dos personagens de Os Invisiveis e Fábula Urbana poderiam ser considerados invisiveis em nossa sociedade atual. Sua mera presença em ambas as narrativas é um indicativo daquilo que podemos considerar uma tentativa de desarticulação do status quo. Para melhor explicar essa afirmação, é essencial observar como esses personagens são caracterizados tanto verbal quanto visualmente.

$\mathrm{Na}$ terceira página dupla (p. 12-13) de Os Invisiveis, o texto escrito diz apenas: "Era assim ao sair de casa com seu pai pela manhã...", enquanto a ilustração mostra o menino, de mãos dadas com o pai, que se volta e acena para um gari (ou um zelador de prédio, ou um catador de lixo) que segura um saco de lixo na mão. Ao fundo, uma caçamba com outros sacos de lixo e garrafas espalhadas pelo chão ajudam a explicitar o contexto. Em quatro cores - preto, branco, laranja e cinza - e onze palavras, Tino Freitas e Renato Moriconi constroem uma cena do cotidiano em que a imaginação se faz presente na conjunção entre palavras e ilustração.

Os invisíveis do livro de Freitas e Moriconi são imagens em sombra, silhuetas sem rosto, sem traços distintivos; pode-se enxergar através deles. Os invisiveis possuem densidade, um peso que é marcado pelo cinza que lhes dá forma. Moriconi ${ }^{75}$ explica que um de seus desafios foi representar as personagens sem reforçar estereótipos. Por isso buscou uma solução para que não precisasse dar ao leitor informações como tipo de vestimenta e traços físicos específicos que, para ele, seriam um problema nessa obra. O autor diz:

Cheguei à conclusão de que o uso de silhuetas poderia me livrar de várias informações indesejadas. Creio que não consegui criar uma narrativa visual neutra de conceitos e preconceitos, frutos da minha visão de mundo, mas penso que consegui reduzir a possibilidade de uma interpretação distante da qual quis comunicar (MORICONI, inédito, 2014).

Particularmente significativa, nesse sentido, é a página dupla 16-17 que apresenta o passeio do menino com seu avô no centro da cidade. As

\footnotetext{
${ }^{75}$ Em entrevista por email.
} 
Invisíveis na cidade: invisibilidade social nos livros ilustrados contemporâneos | 191

duas páginas são recobertas por silhuetas negras de pessoas que formam uma multidão. O campo laranja da visão superpoderosa do menino atravessa a página dupla, da direita para a esquerda, focaliza e destaca uma pessoa que toca violão com o chapéu virado a seus pés. No meio da multidão, todos são anônimos. Não há rostos discerníveis, não há indivíduos, todos os contornos das pessoas são iguais.

A representação dos personagens em Fábula Urbana, por outro lado, é bastante clara e direta. O menino que protagoniza a história é negro e pequeno, especialmente quando comparado ao homem branco, alto, vestido com um terno. O contraste é realçado pela vestimenta do menino - camiseta grande demais e bermudas esfarrapadas. Os tênis, apesar de fazerem, na ilustração, referencia a uma marca bastante conhecida, estão bastante sujos e são amarrados com um barbante em vez de cadarços. Tudo isso se sabe não apenas por meio das ilustrações, mas também através da voz do próprio homem de terno que diagnostica:

O figurino não parecia adequado ao personagem meninode-rua-clássico, que exige: calção surrado, pés descalços, cobertor fedorento jogado nas costas nuas. Não. Talvez graças a esse artifício, o de fugir ao figurino-padrão da miséria e do abandono, conseguia o menino pobre burlar a segurança e invadir o reino encantado e proibido dos shopping centers (REZENDE JR. e COELHO, 2014, p. 17).

Se por um lado o personagem adulto narrador nos torna clara a imagem que faz do menino, por outro lado, da opinião que o menino faz dele, do homem de terno, pouco podemos afirmar já que o homem de terno é também o narrador. Pode-se, no entanto, inferir que o menino dirige-se ao homem com a segurança de poder fazê-lo, ou seja, ele não se sente intimidado pela figura do homem, pelo modo como se veste e nem por seu tamanho.

No que se refere às representações verbo-visuais dos personagens nos dois livros, é importante notar que, apesar de trazerem, ambos, meninos como protagonistas, os mesmos se posicionam em extremos distintos da sociedade sendo que um representa uma camada mais alta da mesma enquanto o outro representa uma esfera socioeconômica mais baixa. Também são opostas as posições sociais que ocupam quase todos os adultos que se relacionam com essas crianças. Vale dizer, portanto, que a caracterização dos personagens, em Os Invisiveis e em Fábula Urbana, é 
marcada por uma série de contrastes tanto artísticos quanto representacionais.

\section{Espaços Urbanos}

A cidade moderna é o palco para o desfile de seres anônimos e invisíveis, cada qual imbuído das tragédias e perigos do cotidiano. $\mathrm{O}$ medo dos seres fantásticos dos contos da infância, das bruxas e do lobomau, se manifesta, então, como medo do outro - ladrão, mendigo, aproveitador - a quem se ignora, de quem se foge, e de quem é importante se afastar o mais rápido possivel após a leitura dos marcadores sociais que indicam seu potencial de vilão. Na cidade moderna, os espaços são organizados de modo a combater esses medos pois criam bloqueios físicos e psíquicos que vedam a presença de tais ou quais grupos sociais a tais ou quais lugares específicos. Bauman propõe o conceito de mixofobia para designar este processo "que impele a procurar ilhas de semelhança e de igualdade no meio do mar da diversidade e da diferença" (2009, p. 40). Evitar o contato é, portanto, proteger-se dos perigos que rondam os bosques de prédios e calçadas.

Em alguns espaços públicos, contudo, esse contato é inevitável. Os Invisíveis e Fábula Urbana apresentam, cada qual a seu modo, exemplos de encontros cotidianos que só se dariam em um espaço urbano, fazendo com que o cenário não seja mero palco para as ações que se desenrolam, mas sim espaço de representatividade simbólica. No caso do primeiro, o texto verbal faz referencia explícita a elementos próprios da cidade: supermercado, escola (à qual o protagonista chega de carro), centro. Já no segundo, o elemento cidade está plasmado por todo o texto e paratexto desde o título até as ilustrações. A maior parte da ação, no entanto, se desenrola no interior de um shopping. Para Dalcastagné,

A cidade é um símbolo da sociabilidade humana, lugar de encontro e de vida em comum - e, neste sentido, seu modelo é a polis grega. Mas é também um símbolo da diversidade humana, em que convivem massas de pessoas que não se conhecem, não se reconhecem ou mesmo se hostilizam; e aqui o modelo não é mais a cidade grega, e sim Babel. Mais até do que a primeira, esta segunda imagem, a da desarmonia e da confusão, é responsável pelo fascínio que as cidades exercem, como locais em que se abrem todas as possibilidades (2003, p. 34). 
As possibilidades de encontro, as tensões geradas, e as possiveis transformações decorrentes dos mesmos só poderiam ocorrer no espaço das cidades que oferecem alguma oportunidade de vida em comum.

\section{Relações - Interações}

O que ambos os títulos apresentam como elemento divergente é a relação que se estabelece entre os personagens dessas duas narrativas. Os dois meninos são elementos chave para o desenvolvimento das duas narrativas. Contudo, apesar de podermos dizer que ambos sofrem algum tipo de "transformação" ao longo da narrativa, os livros não tratam, propriamente dito, do processo de amadurecimento dos meninos, divergindo, portanto, do padrão Bildungsroman comumente associado à produção literária para crianças e jovens. $O$ que parece ser central ao desenvolvimento da narrativa em ambos os títulos é o modo como esses meninos interagem com os adultos que os acompanham em ditas narrativas.

De acordo com Dalcastagné,

As desigualdades incorporadas na organização do espaço urbano podem ser simplesmente aceitas como dados e, de alguma maneira, naturalizadas; podem ser problematizadas, de forma a revelar os padrões de dominação e opressão subjacentes; ou podem ser tensionadas, por narrativas que as subvertem (DALCASTAGNÉ, 2015, p. 12).

Veremos como os personagens dos livros analisados se comportam, revelando padrões de relacionamento que podem ser observados na sociedade atual, mas também problematizando-os e apresentando desenlaces que subvertem os desfechos comumente (ou logicamente) esperados.

$\mathrm{Na}$ primeira cena de Os Invisiveis, a solidez do pai e do filho, plasmada em negro, contrasta com o cinza difuso da pessoa, ao fundo, que segura um saco de lixo. Também o gesto de aceno do menino tornase incerto ao penetrar no campo alaranjado do raio que deixa os invisíveis, visíveis. Um aceno de mão não notado, não percebido pelo pai que olha adiante, corpo e rosto voltados para o lado oposto. Assim também acontece na cena em que a mãe dirige o carro enquanto o menino, no banco de trás, observa o malabarista do sinal e ainda na cena 
com a avó que sai do supermercado levando as compras enquanto o menino entrega algo para um pedinte que está sentado junto à porta de entrada (p.14-15 e 18-19). Todas as interações entre o menino e os invisiveis acontecem às costas dos adultos que o acompanham o que se poderia ler como um retrato da vida moderna em que, no decorrer do dia-a-dia, os movimentos se tornam automáticos e eliminam-se contatos, intercâmbios, trocas de olhares. Elimina-se, até, a percepção daquilo que acontece em nosso entorno imediato.

A mudança que se dá no protagonista a partir da página dupla 2223 é explicitada por suas ações, narradas pelo texto escrito, e também pela repetição de elementos visuais que haviam aparecido nas páginas anteriores. O menino agora é um homem. Os invisíveis novamente aparecem nas cenas que se seguem a essas páginas, mas em proporção ainda maior que nas cenas anteriores. Ocupam mais espaço físico nas páginas duplas e, no entanto, não conseguem alcançar o campo de visão do protagonista que permanece, agora ele, com o rosto sempre virado para o outro lado. A cena de enterro posiciona um coveiro diretamente em frente ao protagonista, numa posição inevitável ao olhar. Pode-se presumir, portanto, que o não ver é uma escolha do protagonista, uma opção de não enxergar alguém que está posicionado diretamente à sua frente e cuja presença não poderia passar desapercebida.

Apesar do contato que o protagonista de Os Invisiveis estabelece com outros personagens ser marcadamente direto, essas interações são sempre breves: uma troca de olhares, um aceno de mão, algo entregue rapidamente para o mendigo - momentos breves que duram pouco. Em Fábula Urbana, por outro lado, a interação entre os dois personagens dura toda a narrativa e é bastante intensa desde o princípio da mesma. $\mathrm{O}$ menino aborda o homem de terno com um pedido bastante incomum "Ei, tio! Me paga um livro?" (REZENDE JR. e COELHO, 2014, p. 5). Não é raro, nos grandes centros urbanos Brasileiros, deparar-se com essa cena: crianças pobres aproximando-se de adultos para pedir-lhes um lanche, um troco, "só uma moedinha"... O que é incomum, no pedido do protagonista, é o objeto de seu desejo. $O$ homem de terno não registra o pedido do menino imediatamente e responde, de modo automático, "Não tenho trocado", resposta essa que ele logo percebe não fazer sentido já que o menino não está lhe pedindo dinheiro.

O diálogo entre os dois segue esse fluxo de perguntas desconcertantes e respostas atrapalhadas que pegam o homem de terno desprevenido e, finalmente, o levam a entrar na livraria, escolher e comprar um livro, e sentar-se para ler uma história com o menino. A 
Invisíveis na cidade: invisibilidade social nos livros ilustrados contemporâneos | 195 partir desse momento de leitura compartilhada, o homem se surpreende com suas próprias memórias de alegria e exaltação. $\mathrm{O}$ encontro com o menino desencadeia no homem uma série de emoções - medo, alívio, nojo, exasperação, nostalgia e, inclusive, felicidade - que são, ao final, engolidas pela culpa. A culpa que o homem sente por esquecer-se de dizer ao menino, no final da leitura do livro, que eles "viveram felizes para sempre".

\section{Para concluir}

Os desenlaces de ambos os livros são amargos e inesperados. De acordo com Colomer (2005, p. 208), o final das histórias é um elemento decisivo pois tanto serve para dar sentido à narrativa como para provocar a reação emotiva do leitor. Por essa razão, é surpreendente encontrar uma conclusão que foge à regra dos finais reconfortantes e felizes, tão próprias da LIJ até quase o fim do século XX, em que as dificuldades são superadas e os conflitos se resolvem e trazem esperança aos leitores mais jovens. Ainda de acordo com Colomer (2005, p.208), no entanto, têm sido mais e mais comuns na produção atual de LIJ os finais abertos, os finais negativos e ainda aqueles que podem ser considerados positivos, porém que tratam da aceitação do conflito em vez de sua resolução. É certo que essa mudança veio acompanhada de grandes debates que giram em torno da capacidade das crianças de compreender e se relacionar com esses novos desenlaces. Essas mudanças, tanto nas estruturas narrativas da LIJ quanto nos debates que as acompanham, permitem que se perceba as transformações no próprio tecido da literatura infantil. Segundo Colomer (2005, p. 215), sua produção atual tem variado no tratamento dos temas e tem experimentado com as fronteiras das formas convencionais de contá-los.

Vemos que los libros se han puesto al día en sus temas y valores cuando hablamos de los conflictos psicológicos que abordan o de la transgresión de los antiguos tabúes y cuando constatamos que el humor, el afecto, la relativización de la jerarquia, la consideración del otro, la iniciativa personal o la imaginación son realizados como cualidades valiosas. Pero también vamos que los libros se han hecho más extraños y sorprendentes al atreverse a jugar con el lector, a volverse metaficcionales, a incorporar la imagen y los recursos materiales a la construcción de la historia, a vulnerar las 
fronteras de los géneros o a incrementar la intertextualidad. (COLOMER, 2005, p.215) ${ }^{76}$

O perturbador desenlace de Os Invisiveis se realiza em uma página dupla completamente negra, onde se lê apenas, em branco: "E o menino envelheceu esquecendo que um dia teve um superpoder." Na dualidade do branco e preto, percebe-se a ausência das ilustrações, a qual não é, por sua vez, menos significativa do que a presença das ilustrações em todas as páginas anteriores. A ausência é, nesse caso, também parte da narrativa e de seu desenlace e ela contribui para a produção de sentido com o ominoso do negro e a luminosidade do branco que nega, em definitivo, uma recuperação da sensibilidade do protagonista.

A conclusão de Fábula Urbana, apesar de surpreendente, difere daquela de Os Invisiveis no sentido em que parece abrir uma porta em vez de fechá-la. O desfecho também é eficiente em sua capacidade de provocar uma reação emocional no leitor, conforme apontado por Colomer (2005). A forma como a narrativa se desenvolve envolve o leitor no sentimento de culpa experimentado pelo homem de terno, apagando as fronteiras emocionais de "dentro" e de "fora" da história. As palavras são trabalhadas de modo tal a elevar a tensão no momento em que o homem sai do ambiente seguro do shopping para encarar a ferocidade da selva urbana com todos os seus perigos. Espera-se o pior. Novamente, percebem-se os contrastes que marcam a relação entre os personagens pois lá fora, na rua, o menino que se aproxima do carro do homem não é mais tão pequeno e indefeso. Fica estabelecido o jogo de perspectiva que vai mudando a partir do lugar de onde fala o narrador. Homem, menino, e cidade, entrelaçam-se e todas as incoerências das relações humanas nos grandes centros urbanos brasileiros vêm à tona no momento em que uma voz pergunta: "Tio, me ensina a ler?"

\footnotetext{
${ }^{76}$ Vemos que os livros atualizaram seus tema e valores quando falamos dos conflitos psicológicos que abordam ou da transgressão dos antigos tabus e quando constatamos que o humor, o afeto, a relativização da hierarquia, a consideração do outro, a iniciativa pessoal ou a imaginação são realizados como qualidades valiosas. Mas também vemos que os livros se tornaram mais estranhos e surpreendentes ao se atreverem a jogar com o leitor, a se tornarem metaficcionais, a incorporar a imagem e os recursos materiais à construção da história, a vulnerar as fronteiras dos gêneros ou a incrementar a intertextualidade.
} 
Invisíveis na cidade: invisibilidade social nos livros ilustrados contemporâneos | 197

\section{REFERÊNCIAS}

BAUMAN, Z. Confiança e medo na cidade. Trad. Eliana Aguiar. Rio de Janeiro: Ed. Zahar, 2009.

COLOMER, T. Álbumes Ilustrados y Cambio de Valores en el Cambio de Siglo. In: COLOMER, T., KUMMERLING-MEIBAUER, B. \& SILVA-DÍAZ M.C. (Org.) Cruce de Miradas: Nuevas aproximaciones al libro-álbum. Caracas: Banco del Libro, 2010, Barcelona: GRETEL, 2010.

ELLISON, Ralph. O Homem Invisivel. Trad. de Márcia Serra. Rio de Janeiro: Marco Zero, 1990.

FREITAS, Tino. Os Invisíveis. Ilustrações de Renato Moriconi. Rio de Janeiro: Casa da Palavra, 2013.

DALCASTAGNÉ, R. Sombras da cidade: o espaço na narrativa brasileira contemporânea. In: Estudos de Literatura Brasileira Contemporânea. No. 21, p. 33-53, 2003.

DALCASTAGNÉ, R. e AZEVEDO, L. (org.) Espaços possiveis na literatura brasileira contemporânea. São Paulo: Zouk, 2015.

NIKOLAJEVA, M. e SCOTT, C. Livro Ilustrado: palavras e imangens. São Paulo: Cosac Naify, 2011.

REZENDE JÚNIOR, J. Fábula Urbana. Ilustrações de Rogério Coelho. Rio de Janeiro: Edições de Janeiro, 2014.

SIPE, L. How Picturebooks Work: a semiotically framed theory of text-picture relationships. Children's Literature in Education 29, p. 97-108, 1998.

VAN DER LINDEN, S. Para Ler o Livro Ilustrado. São Paulo: Cosac Naify, 2011.

album [s]. Paris: Actes Sud, 2013.

WILliAMS, R. O Campo e a Cidade. São Paulo: Cia. Das Letras, 2011. 
198 | Silvana Gili

Recebido em: 29/06/2016

Aceito em: 28/08/2016 